\title{
Decreased BMP-7 and p-Smad1/5/8 expression, and increased levels of gremlin in hepatocellular carcinoma
}

\author{
LINA WANG $^{1 *}$, QIN DING $^{1 *}$, LI ZHAO $^{2}$, YU PAN $^{1}$, ZHENGXIA SONG $^{1}$, YANAN QIN $^{1}$ and XUEBING YAN ${ }^{1}$ \\ Departments of ${ }^{1}$ Infectious Disease and ${ }^{2}$ Respiratory, The Affiliated Hospital of Xuzhou Medical University, \\ Xuzhou, Jiangsu 221002, P.R. China
}

Received December 29, 2016; Accepted November 21, 2017

DOI: $10.3892 / \mathrm{ol} .2018 .8918$

\begin{abstract}
The aim of the present study was to investigate the expression of bone morphogenetic protein-7 (BMP-7), gremlin, and $\mathrm{p}-\mathrm{Smad} / 1 / 5 / 8$ in carcinomatous and para-carcinoma tissue specimens from patients with hepatocellular carcinoma (HCC). The association of serum BMP-7 levels with clinicopathological parameters was examined to assess its relevance as a clinical biomarker for HCC. A total of 27 patients with HCC and 7 healthy subjects were included. Gene expression levels of BMP-7 and p-Smad1/5/8 were examined by reverse transcription-quantitative polymerase chain reaction. Immunohistochemical and western blot analysis were performed to determine the protein expression of target genes. The serum levels of BMP-7 were assessed by enzyme linked immunosorbent assay. The mRNA and protein expression of BMP-7 and gremlin were significantly down- and upregulated in HCC tumor tissues, respectively, compared with para-carcinoma tissues $(\mathrm{P}<0.05)$. The association of BMP-7 and gremlin expression with the differentiation status of $\mathrm{HCC}$ was also analyzed. There was a relatively higher level of BMP-7 and a lower level of gremlin expression in tumor tissues from patients with highly differentiated HCC when compared with poorly or moderately differentiated HCC (BMP-7, $\mathrm{F}=42.29, \mathrm{P}<0.01$; gremlin, $\mathrm{F}=37.93, \mathrm{P}<0.01)$. Furthermore, the level of BMP-7 and p-Smad1/5/8 was decreased in patients with advanced stages of $\mathrm{HCC}$, when compared with stage I HCC. The findings from the present study suggest that the BMP-7/p-Smad signaling pathway may be involved in the pathogenesis of HCC. The serum levels of BMP-7 may serve as a potential biomarker for HCC.
\end{abstract}

Correspondence to: Dr Qin Ding, Department of Infectious Disease, The Affiliated Hospital of Xuzhou Medical University, No. 9 North Kunpeng Road, Xuzhou, Jiangsu 221002, P.R. China E-mail: kgylan163@163.com

*Contributed equally

Key words: bone morphogenetic protein-7, gremlin, p-Smad, hepatocellular carcinoma

\section{Introduction}

Liver cancer is a highly prevalent malignancy worldwide, and is associated with high mortality. According to Global Cancer Statistics (2012), liver cancer accounts for 521,000 and 224,500 mortalities among men and women, respectively (1). Hepatocellular carcinoma (HCC) accounts for $>70 \%$ of all primary liver cancer (2). Due to its asymptomatic nature, patients with HCC are typically diagnosed at an advanced stage (3). Hence, there is an urgent requirement to identify biomarkers for early detection of HCC to improve patient prognosis (3).

Bone morphogenetic proteins (BMPs), which are homodimeric members of the transforming growth factor- $\beta$ (TGF- $\beta$ ) superfamily, have been implicated in the pathogenesis of human malignancies (4). To date, $>20$ human BMPs have been identified, among which BMP-7 levels have been demonstrated to be closely associated with HCC (1). The anti-tumorigenic potential of BMP-7 has been detected in several human malignancies, including breast cancer and glioblastoma (5-7). Hou et al (8) indicated that BMP-7 attenuates liver fibrosis, which may develop into HCC. Furthermore, inhibition of BMP-7 signaling was revealed to facilitate invasive growth of HCC cells (9). The BMP family members mediate signal transduction by binding to their receptors, which triggers the phosphorylation of Smad proteins 1, 5, and 8 (Smad1/5/8) $(10,11)$. However, the potential association between BMP-7 and Smad signaling pathway in HCC has not yet been fully elucidated.

Gremlin, an endogenous antagonist of BMP-7, inhibits the binding of BMP-7 to its receptor, thereby, inhibiting Smad phosphorylation and the downstream signaling cascade (12). Gremlin protein, secreted by fibroblasts has been revealed to be a biomarker of liver fibrosis (13). Gremlin promotes stem cell maturation and proliferation via inhibition of the BMP signaling pathway, which in turn accelerates hepatic fibrosis and carcinogenesis (14). These findings indicate that the BMP signaling pathway may serve as an endogenous self-defense mechanism against carcinogenesis and progression of HCC.

In the present study, it was hypothesized that the BMP-7 and Smad signaling pathway may serve a pivotal role in the prevention of HCC. Therefore, HCC samples with varied tumor differentiation status and at different clinical stages were included. Expression levels of BMP-7, gremlin, and Smad1/5/8 
in carcinomatous and their adjacent non-carcinomatous (normal) tissues were assessed. The findings from the present study indicate the clinical significance of these indices in predicting the disease status of HCC.

\section{Materials and methods}

Reagents. Rabbit anti-human anti-BMP-7 antibody was obtained from Abcam, Cambridge, UK (cat. no. ab56023). Rabbit anti-human anti-gremlin antibody was purchased from Wuhan Boster Biological Technology, Ltd., Wuhan, China (cat. no. BA2287). Rabbit anti-human anti-p-Smad1/5/8 antibody was purchased from Santa Cruz Biotechnology, Inc., Dallas, TX, USA (cat. no. sc-12353-R). The 3,3'-diaminobenzidine tetrahydrochloride (DAB) kit was obtained from ZSGB-Bio, Beijing, China. RNAstore solution, TIANScript first-strand cDNA synthesis kit, and SuperReal PreMix Plus SYBR Green were obtained from Tiangen Biotech Co., Ltd., Beijing, China. RIPA lysis buffer and phenylmethylsulfonyl fluoride (PMSF) were obtained from Beyotime Institute of Biotechnology, (Haimen, China).

Patients. A total of 27 patients with HCC who underwent curative surgical resection at the Department of General Surgery, The Affiliated Hospital of Xuzhou Medical University, (Xuzhou, China), between November 2014 and August 2015, were included in the present study. Inclusion criteria are as follows: i) Diagnosis of HCC according to the diagnostic criteria recommended by the Professional Committee of Chinese Anti-Cancer Association of Liver Cancer in 2001 (15); ii) not received surgical, interventional or radiation therapy prior to sample collection. Tumor-node metastasis (TNM) staging was performed based on the criteria of the American Joint Committee on Cancer (AJCC) (16). Pathological examination was conducted and tumor differentiation was recorded. Baseline demographic and clinical characteristics of patients are listed in Table I. In addition, a total of 7 healthy subjects were enrolled in the present study. Written informed consent was obtained from all subjects prior to their enrollment in the study. The study was approved by the Ethics Committee at the Affiliated Hospital of Xuzhou Medical University (Xuzhou, China).

Sample collection. A total of $\sim 100 \mathrm{mg}$ tumor tissues or para-carcinoma tissues ( $3 \mathrm{~cm}$ away from the tumor margin) were collected following curative surgical resection for polymerase chain reaction (PCR) analysis. The tissues were washed in phosphate buffer solution (PBS). The samples to be used for RNA extraction were incubated in $1 \mathrm{ml}$ RNAstore solution at $4^{\circ} \mathrm{C}$ overnight and stored at $-80^{\circ} \mathrm{C}$ until further use. For western blot analysis, samples were grinded into pieces, immediately immersed in liquid nitrogen $\left(-196^{\circ} \mathrm{C}\right)$, followed by long-term storage at $-80^{\circ} \mathrm{C}$. For histological examination, tissue samples were fixed in $4 \%$ paraformaldehyde solution for $24 \mathrm{~h}$ at room temperature. In addition, fasting venous blood samples were collected from patients with HCC prior to operation and from healthy subjects. The samples were incubated at room temperature for 1-2 $\mathrm{h}$, followed by centrifugation at 2,200 $\mathrm{x}$ g for $5 \mathrm{~min}$ at room temperature. The serum was separated and stored at $-80^{\circ} \mathrm{C}$ until use.
Table I. Demographic and clinical characteristics of subjects.

\begin{tabular}{lcc}
\hline Parameters & $\begin{array}{c}\text { Patients with } \\
\text { HCC }(\mathrm{n}=27)\end{array}$ & $\begin{array}{c}\text { Healthy } \\
\text { subjects }(\mathrm{n}=7)\end{array}$ \\
\hline Sex $(\%)$ & $21(78)$ & $5(71)$ \\
Male & $6(22)$ & $2(29)$ \\
Female & $57 \pm 11$ & $54 \pm 14$ \\
Age, years & & - \\
TNM staging (\%) & $3(11)$ & - \\
I & $12(45)$ & - \\
II & $9(33)$ & - \\
III A & $3(11)$ & - \\
III B & & - \\
Differentiation $(\%)$ & $4(15)$ & - \\
Poor & $15(56)$ & \\
Moderate & $8(29)$ & \\
High & & \\
\hline
\end{tabular}

HCC, hepatocellular carcinoma; TNM, tumor-node metastasis.

Reverse transcription-quantitative polymerase chain reaction (RT-qPCR). A total of $100 \mathrm{mg}$ of the tissue samples were grinded, and the total RNA was extracted using TRIzol reagent according to the manufacturer's protocol (Ambion; Thermo Fisher Scientific, Inc., Waltham, MA, USA). Total RNA $(1 \mu \mathrm{g})$ was reverse transcribed using TIANScript first-strand cDNA synthesis kit, according to the manufacturer's protocol. Synthesized cDNA was used for RT-qPCR amplification using SuperReal PreMix Plus SYBRGreen, and a sequence detection system (Roche Diagnostics, Basel, Switzerland). The PCR primers were synthesized by Takara Biotechnology Co., Ltd., (Dalian, China) and Sangon Biotech Co., Ltd., (Shanghai, China). The primer sequences for target genes were as follows: BMP-7, forward, 5'-ACCAGAGGCAGGCCTGTA AGA-3'; and reverse, 5'-CTCACAGTTAGTAGGCGGCGT AG-3'; gremlin, forward, 5'-GCCCTCGGGAGCCACAAA CC-3'; and reverse, 5'-GCAGCAGGAGTCGCGGTGAG-3'; $\beta$-actin, forward, 5'-ACTAACCGCTTCTGTTACGG-3'; and reverse, 5'-ATGCAACGACACTGCTTCAC-3'. The PCR reaction system included $10 \mu \mathrm{l}$ 2X SuperReal PreMix Plus, $0.6 \mu 1$ forward primer, $0.6 \mu 1$ reverse primer, $1 \mu \mathrm{l}$ template cDNA and $7.8 \mu \mathrm{l} \mathrm{ddH_{2 }} \mathrm{O}$ to a total volume of $20 \mu \mathrm{l}$. PCR reactions were performed by pre-denaturation at $95^{\circ} \mathrm{C}$ for $15 \mathrm{~min}$, followed by 40 cycles of $95^{\circ} \mathrm{C}$ for $10 \mathrm{sec}, 60^{\circ} \mathrm{C}$ for $20 \mathrm{sec}$ and $72^{\circ} \mathrm{C}$ for $20 \mathrm{sec}$. The predicted product length was $107 \mathrm{bp}$ for BMP-7, $197 \mathrm{bp}$ for gremlin and $151 \mathrm{bp}$ for $\beta$-actin. Each experiment was conducted in triplicate. The relative mRNA expression was calculated using the $2^{-\Delta \Delta \mathrm{Cq}}$ method (17).

Immunohistochemistry. Tissue samples collected after curative surgical resection were embedded in paraffin, and the sections (thickness, $4 \mu \mathrm{m}$ ) were prepared using an automatic tissue processor (RM2235; Leica, Germany). Subsequently, the sections were deparaffinized in xylene (twice, each for $10 \mathrm{~min}$ ), and rehydrated in an ethanol series ( $100 \%$ for $5 \mathrm{~min}$, $90 \%$ for $2 \mathrm{~min}, 70 \%$ for $2 \mathrm{~min}$ and distilled water for $2 \mathrm{~min}$ ). 
The sections were heated in $0.01 \mathrm{M}$ citrate buffer $(\mathrm{pH}$ 6.0) in a microwave. After three washes in PBS, the samples were incubated with $3 \%$ hydrogen peroxide at room temperature, to block the endogenous peroxidase activity. After three washes with PBS (5 for each time) at room temperature, the sections were incubated with $100 \mu \mathrm{l}$ primary antibodies, including rabbit asti-BMP-7 (1:100) and rabbit anti-gremlin (1:200) at $4^{\circ} \mathrm{C}$ overnight as described previously. Immunostaining was performed using rabbit ultra-sensitive two-step kit according to manufacturer's protocol (ZSGB-Bio, Beijing, China). The following day, the samples were washed three times in PBS and probed with horseradish peroxidase (HRP)-conjugated goat anti-rabbit IgG secondary antibody, pre-diluted from the supplier, for $20 \mathrm{~min}$ at $37^{\circ} \mathrm{C}$. After PBS washes, the immunoreactivity was assessed by DAB staining for $3 \mathrm{~min}$ at room temperature. Nuclei were counterstained with hematoxylin. Subsequently, the sections were washed with running tap water for $10 \mathrm{~min}$, followed by dehydration through $95 \%$ ethanol for 5 min and $100 \%$ ethanol for $5 \mathrm{~min}$. After two washes of xylene (each for $5 \mathrm{~min}$ ), the samples were mounted with neutral balsam.

Imaging. Immunoreactivity was analyzed under a phase contrast microscope (BX51; Olympus Corporation, Tokyo, Japan) at x400 magnification. BMP-7 positive cells were identified by a brown-yellow stained cytosol or nuclei. Gremlin-positive cells were defined as those with brown-yellow-stained cell membrane, cytosol or nuclei. A total of five fields of interest were randomly selected from each sample for imaging in order to minimize bias as described previously (18), and the average integral optical density (OD) per area was calculated by Image-Pro Plus software (version 6.0, Media Cybernetics, Inc., Rockville, MD, USA).

Western blotting. A total of $100 \mathrm{mg}$ of tissue samples were lysed in $1 \mathrm{ml}$ RIPA lysis buffer, which contained $10 \mu \mathrm{l}$ PMSF and $7 \mu \mathrm{l}$ protease inhibitor. Following centrifugation at $1,452 \mathrm{x} \mathrm{g}$ for $10 \mathrm{~min}$ at $4^{\circ} \mathrm{C}$, the supernatant was collected. For the determination of protein concentration, bicinchoninic acid (BCA) protein assay kit (Beyotime Institute of Biotechnology) was used. Equal amounts of total protein $(80 \mu \mathrm{g})$ per well were separated by $10 \%$ SDS-PAGE electrophoresis. After electrophoresis, the proteins were transferred on to PVDF membranes, blocked with $5 \%$ non-fat dry milk dissolved in PBS for $3 \mathrm{~h}$ at room temperature (RT) and probed with primary antibodies, including anti-BMP-7 (1:500 dilution) and anti-p-Smad1/5/8 (1:500) antibodies, at $4{ }^{\circ} \mathrm{C}$ overnight. Following four washes with TBST (each for 5-10 $\mathrm{min}$ ), the membranes were incubated with goat anti-rabbit HRP-conjugated secondary antibodies $(1: 4,000)$ for $2 \mathrm{~h}$ at room temperature. After washes with TBST, immunoreactivity was assessed using an enhanced chemiluminescence assay. The immunobands were exposed to X-ray films and scanned. The density of bands was analyzed by Quantity One software 4.62 patch (Bio-Rad Laboratories, Inc., Hercules, CA, USA).

ELISA for cytokine analysis. The serum BMP-7 level was examined by ELISA using a human BMP-7 ELISA kit according to manufacturer's protocol (RayBiotech Inc., GA, USA). The absorbance was measured at $450 \mathrm{~nm}$ using a ClinBio128 microplate reader (Asys Hitech GmbH, Eugendorf, Austria).
Statistical analysis. All data are expressed as the mean \pm standard deviation. The differences between the groups were assessed with unpaired Student's t-test, and multiple group comparisons were performed using one-way analysis of variance following Student-Newman-Keuls post-hoc test. All statistical tests were two-tailed with $\alpha=0.05$. $\mathrm{P}<0.05$ was considered to indicate a statistically significant difference.

\section{Results}

Expression BMP-7 and gremlin in carcinoma andnon-carcinoma tissues of HCC. To investigate the involvement of BMP-7 during carcinogenesis and progression of HCC, the mRNA levels of BMP-7 and its endogenous antagonist gremlin were determined in carcinoma and non-carcinoma tissues of HCC by RT-qPCR. BMP-7 mRNA expression was significantly downregulated in tumor tissues, compared with para-carcinoma tissues $(\mathrm{P}<0.05$; Fig. 1). By contrast, the mRNA expression of gremlin in carcinoma tissues was significantly increased compared with non-carcinoma tissues ( $\mathrm{P}<0.05$; Fig. 1). Immunohistochemical analysis revealed that BMP-7 was predominantly expressed in the nucleus of tumor cells (Fig. 2A). The protein expression of BMP-7 was greatly reduced in carcinoma tissues compared with the non-carcinoma tissues $(\mathrm{t}=11.808, \mathrm{P}<0.01$; Fig. $2 \mathrm{~A}$ and $\mathrm{B})$. Gremlin exhibited a different intracellular distribution pattern compared with BMP-7, as gremlin expression was predominantly detected in the cell membrane and cytosol (Fig. 2). Furthermore, by contrast to BMP-7, gremlin protein was significantly increased in carcinoma tissues compared with non-carcinoma tissues $(\mathrm{t}=-6.182 ; \mathrm{P}<0.01$; Fig. 2C-E). These results indicate that BMP-7 mRNA and protein expression levels were reduced in HCC tissues, and that the level of BMP-7 was negatively associated with that of gremlin.

Expression of BMP-7 and gremlin in HCC tissues at various stages of differentiation. Expression levels of BMP-7 and gremlin in HCC tissues with poor, moderate, and high differentiation status were compared. It was observed that patients with highly differentiated HCC had a relatively higher BMP-7 level but a lower level of gremlin expression (BMP-7, $\mathrm{F}=42.29$, $\mathrm{P}<0.01$; gremlin, $\mathrm{F}=37.93, \mathrm{P}<0.01$; Fig. 3 ). The data of BMP-7 and gremlin in para-carcinoma tissues are presented in Fig. 2. The results from the present study indicate that BMP-7 may be used to predict the tumor differentiation status.

Expression of BMP-7, gremlin and p-Smad1/5/8 in carcinoma tissues of HCC at different clinical stages. To elucidate the role of BMP-7 and gremlin in the regulation of HCC development, gene expression levels in carcinoma tissues at various clinical stages (I, II, IIIA and IIIB) were examined. BMP-7 mRNA expression was gradually reduced with increasing clinical stage $(\mathrm{F}=18.45, \mathrm{P}<0.01)$, while the level of gremlin was elevated in advanced staged HCC tissue samples $(\mathrm{F}=18.45$, $\mathrm{P}<0.01$; Fig. 4). Western blot analysis indicates that BMP-7 protein expression was downregulated in carcinoma tissues compared with non-carcinoma tissues (Fig. 5A and B), which is consistent with the results of PCR and histological analysis (Figs. 1 and 2). Furthermore, BMP-7 levels were decreased with advanced disease progression, since a lower level of BMP-7 expression was detected in samples from patients with stage 


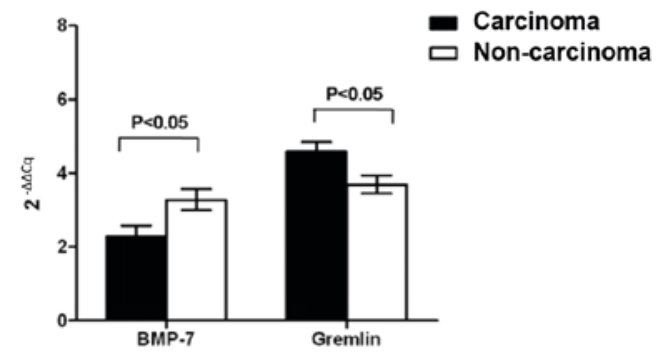

Figure 1. Reverse transcription-quantitative polymerase chain reaction detection of the mRNA levels of BMP-7 and its endogenous antagonist gremlin in carcinomatous and non-carcinomatous tissue specimens from patients with HCC. Non-carcinoma tissues were used as controls. $\mathrm{P}<0.05$ vs. non-carcinoma tissues. BMP-7, bone morphogenetic protein-7; HCC, hepatocellular carcinoma.

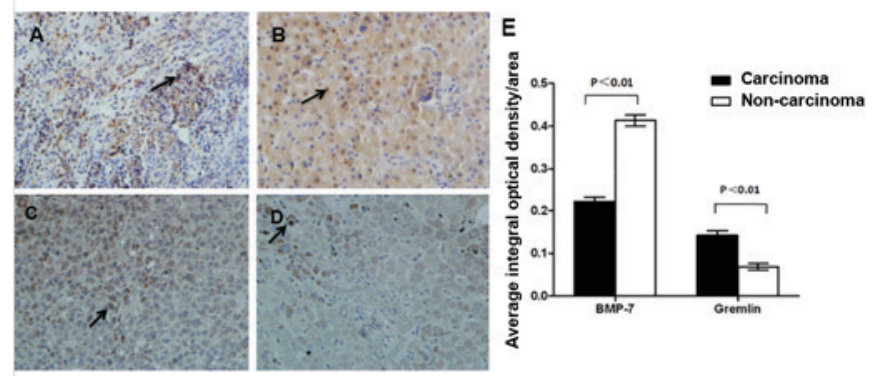

Figure 2. Protein expression of BMP-7 and gremlin in carcinomatous and non-carcinomatous hepatic tissue specimens from patients with HCC. (A) BMP-7 expression in a HCC tissue specimen. (B) BMP-7 expression in a non-carcinomatous (para-carcinoma tissues, $3 \mathrm{~cm}$ away from tumor margin) tissue specimen. (C) Gremlin expression in a HCC tissue specimen. (D) Gremlin expression in a non-carcinomatous tissue specimen. Black arrows indicate representative positive staining. Magnification, $x 400$. (E) The mean integral optical density per area was calculated. Non-carcinoma tissues were used as controls. $\mathrm{P}<0.01$ vs. non-carcinomatous tissues. BMP-7, bone morphogenetic protein-7; HCC, hepatocellular carcinoma.

IIIB HCC compared with stage I HCC samples (Fig. 5A-C). In addition, the expression pattern of $\mathrm{p}$-Smad1/5/8 was similar to that of BMP-7. The level of p-Smad1/5/8 was downregulated in carcinoma tissues, and it was significantly downregulated in advanced stage $\mathrm{HCC}(\mathrm{P}<0.01$; Fig. 5C).

Serum levels of BMP-7. To investigate the potential use of serum BMP-7 levels for the prediction of HCC progression, serum BMP-7 levels in patients with HCC and healthy subjects were compared. Serum BMP-7 levels were relatively high in healthy subjects $(45.41 \pm 5.73 \mathrm{ng} / \mathrm{ml})$, whereas the levels of BMP-7 in patients with HCC were decreased and the level of BMP-7 decreased to varying degrees depending on the stage of the disease. The reduction in serum BMP-7 levels was observed to be associated with disease progression since patients with more advanced stages of HCC generally exhibited lower serum level of BMP-7 (stage I, 38.35 \pm 5.81 ; stage II, 28.24 \pm 2.82 ; stage IIIA, 20.79 \pm 3.72 ; stage IIIB, 10.40 $\pm 2.15 ; \mathrm{F}=74.467 ; \mathrm{P}<0.01$; Fig. 6).

\section{Discussion}

HCC is a severe hepatic disorder associated with a high mortality rate (19). Patient prognosis is typically poor as the

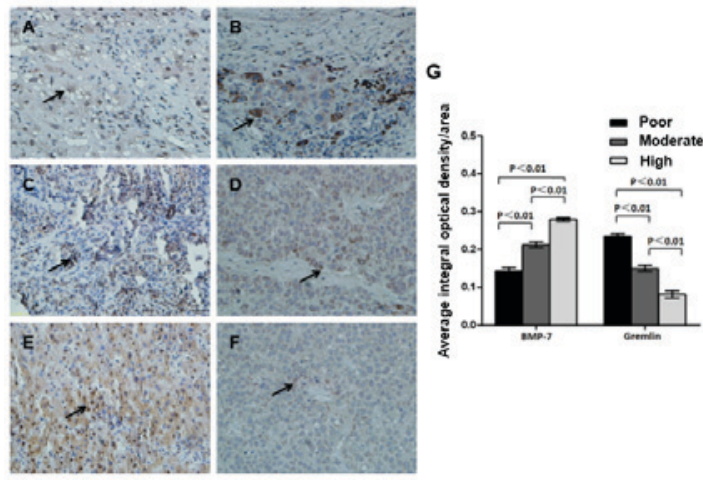

Figure 3. Protein expression of BMP-7 and gremlin in HCC tissue specimens with varied differentiation status. Carcinoma tissue samples were obtained from patients with $(\mathrm{A}, \mathrm{B})$ poor, $(\mathrm{C}, \mathrm{D})$ moderate or $(\mathrm{E}, \mathrm{F})$ high differentiation. Protein expression of (A,C,E) BMP-7 and (B,D,F) gremlin were analyzed by immunohistochemistry. Magnification, x400. (G) Mean integral optical density per area was calculated. Protein expression of BMP-7 and gremlin in carcinoma tissue samples derived from patients at varied differentiation were compared. $\mathrm{P}<0.01$. BMP-7, bone morphogenetic protein-7; HCC, hepatocellular carcinoma.

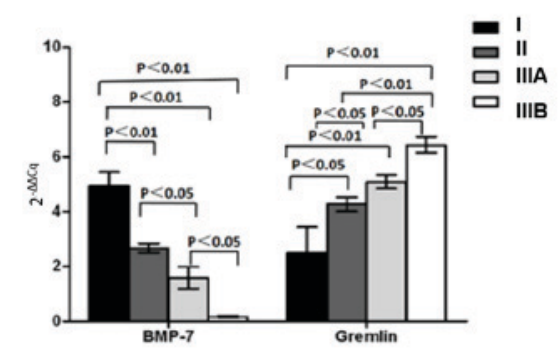

Figure 4. Reverse transcription-quantitative polymerase chain reaction of BMP-7 and gremlin mRNA expression in HCC tissue specimens from patients at different clinical stages (stage I, II, IIIA or IIIB). mRNA levels of BMP-7 and gremlin in HCC tissue samples derived from patients at varied clinical stages were compared. $\mathrm{P}<0.05$ or $\mathrm{P}<0.01$. BMP-7, bone morphogenetic protein-7; HCC, hepatocellular carcinoma.

majority of cases are diagnosed at an advanced stage (19). Understanding the molecular mechanisms that underlie hepatocarcinogenesis may help facilitate therapeutic decision-making in clinical settings. In the present study, it was demonstrated that the BMP-7-Smad signaling pathway may have an anti-tumorigenic function in the progression of HCC.

In the present study, it was observed that there was a lower level of BMP-7 expression in HCC tumor tissues compared with non-carcinoma tissues. BMP-7 expression appeared to be directly associated with the extent of tumor differentiation and was inversely associated with the clinical stage. Therefore, these results indicate that BMP-7 may act as a tumor suppressor, and that the loss of BMP-7 may accelerate the progression of HCC.

Consistent with the findings in the present study, Yang et al (20) demonstrated that BMP-7 was able to block the development of hepatic fibrosis via inhibition of TGF- $\beta 1$ production and increase in gremlin generation. Similarly, Wang et al (21) reported that BMP-7 mediated the prevention of liver fibrosis and hepatic stellate cell activation in mice injected with carbon tetrachloride (21). In addition, exogenous administration of BMP-7 was demonstrated to suppress hepatic fibrosis in rodents via regulation of the Smad signaling pathway (22). 


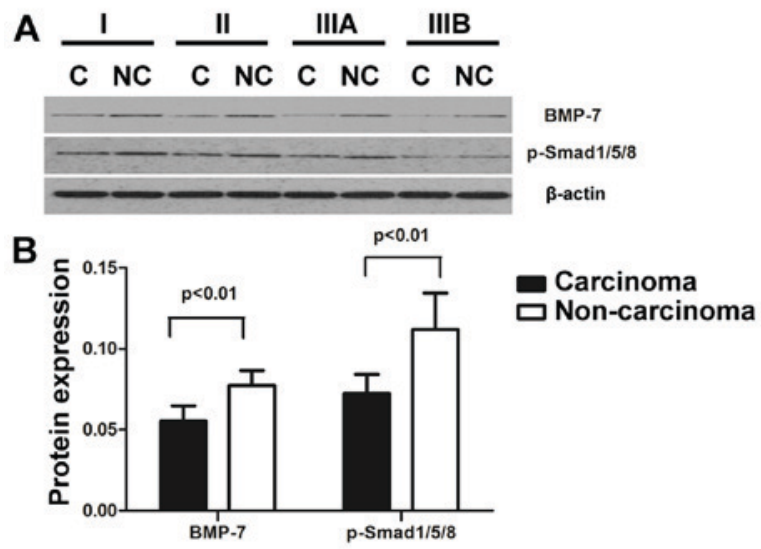

C

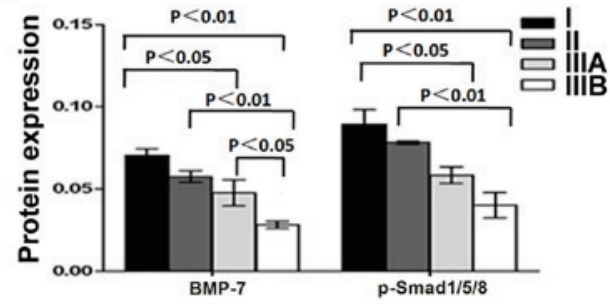

Figure 5. Western blotting of BMP-7 and p-Smad1/5/8 protein expression in carcinomatous and non-carcinomatous hepatic tissue specimens from patients with HCC at different clinical stages (I, II, IIIA, or IIIB). (A) Representative immunoblots of BMP-7 and p-Smad1/5/8. (B) Protein expression in carcinoma and non-carcinoma tissues was quantified. (C) Protein expression in carcinoma tissues at stages I, II, IIIA or IIIB were quantified. Protein expression of BMP-7 and p-Smad1/5/8 in non-carcinomatous tissue samples and $\mathrm{HCC}$ tissue samples at various clinical stages were compared Non-carcinomatous tissue samples were used as controls. $\mathrm{P}<0.05$ or $\mathrm{P}<0.01$. BMP-7, bone morphogenetic protein-7; HCC, hepatocellular carcinoma.

In the present study, protein expression of $\mathrm{p}$-Smad $1 / 5 / 8$ was observed to be downregulated in HCC tissues compared with non-carcinoma tissues. The reduced level of $\mathrm{p}$-Smad1/5/8 was associated with advanced stages of HCC, which indicates that BMP-7/Smad signaling pathway may act as a self-defense mechanism against carcinogenesis and progression of HCC. BMP-7/Smad signals may have anti-fibrogenic and anti-hepatocarcinogenic effect during the pathogenesis of $\operatorname{HCC}(8,9,14,23)$. By contrast, Li et al (24) reported that the mRNA and protein expression of BMP-7 was upregulated in HCC cells compared with normal hepatic cells. Furthermore, increased BMP-7 levels were associated with poor prognosis in patients with HCC, which implies that BMP-7 may serve as an oncogene for HCC. This discrepancy may have been caused by the small sample size. Therefore, future studies are required which should include larger sample sizes of patients with HCC. Although the molecular mechanisms involved in BMP-7/Smad-regulated HCC development remain unclear, it is possible that BMP-7 counteracts the actions of TGF- $\beta$, which is known to contribute to epithelial-mesenchymal transition (EMT) of hepatocytes (25). In addition, efforts should be made to investigate the regulatory role of BMP-7/Smad signaling pathway in the EMT process in HCC using cell culture and rodent models.

Notably, serum BMP-7 levels were also reduced in patients with HCC, particularly in patients with advanced stages of HCC, as compared with healthy subjects. This particular finding indicates a potential clinical relevance of serum BMP-7 level for the

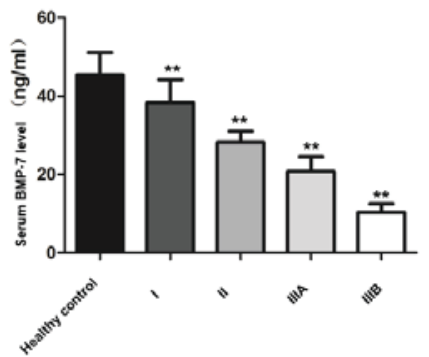

Figure 6. ELISA analysis of serum BMP-7 levels in healthy subjects and patients with HCC. Healthy subjects ( $n=7)$; HCC stage I ( $n=3)$, II ( $n=12)$, IIIA $(\mathrm{n}=9)$ and IIIB $(\mathrm{n}=3)$. Tissues from healthy subjects were used as controls. ${ }^{* *} \mathrm{P}<0.01$ vs. Healthy control. ELISA, enzyme linked immunosorbent assay; BMP-7, bone morphogenetic protein-7; HCC, hepatocellular carcinoma.

prediction of $\mathrm{HCC}$ stage. In agreement with the present findings, Aktug et al (26) demonstrated an association between serum BMP-7 levels with hepatic fibrosis. It was reported that higher BMP-7 serum levels were observed in patients with grades I, II, III and IV liver fibrosis, while the levels were significantly lower in patients with severe hepatic failure (grade V) compared with healthy subjects (26). These findings suggest an anti-inflammatory and anti-fibrogenic role of BMP-7. Plasma levels of BMP-7 in patients with chronic liver disease were shown to be significantly higher than those in healthy subjects (27). These findings indicate a potential use of serum BMP-7 levels for prediction of the extent of liver fibrosis and carcinogenesis.

The current study has several limitations. Firstly, the sample size is relatively small, and therefore confirmation of the inferences drawn requires evidence from larger studies. Secondly, the patients recruited for the present study were predominantly male. The effect of gender bias on the present results cannot be ruled out. Thirdly, in the diagnosis of hepatocellular carcinoma, $\alpha$-fetoprotein (AFP) is a marker of liver cancer, although its sensitivity is not high (28). Fourthly, negative and positive controls of BMP-7 and gremlin proteins were not included. Therefore, future studies will be conducted with a more robust design. Finally, correlation analysis between the expression level of BMP-7 and the characteristics of the patients has not yet been conducted.

In summary, the present study demonstrated that the levels of BMP-7 and p-Smad1/5/8 are decreased, while the level of gremlin is increased in HCC, compared with non-carcinoma tissues. These findings suggest a potential involvement of BMP-7/Smad signaling pathway in the carcinogenesis and progression of HCC. In addition, serum BMP-7 levels may have potential diagnostic value as a marker for hepatic carcinogenesis.

\section{Acknowledgements}

Not applicable.

\section{Funding}

The present study was supported by National Natural Science Foundation of China (grant no. 81371867) and Educational Commission of Jiangsu Province of China (grant no. 08KJD320012). 


\section{Availability of data and materials}

The datasets used and/or analyzed during the current study are available from the corresponding author on reasonable request.

\section{Authors' contributions}

LW prepared samples, performed experiments and was a major contributor in writing the manuscript. QD contribution to conception and design. LZ, YP and XY performed analysis and interpretation of data. ZS and YQ participated in acquisition of data. All authors read and approved the final manuscript.

\section{Ethics approval and consent to participate}

Written informed consent was obtained from all subjects prior to their enrollment in the present study. The present study was approved by the Ethics Committee at the Affiliated Hospital of Xuzhou Medical University (Xuzhou, China).

\section{Consent for publication}

Patients provided written consent for the publication of the present study.

\section{Competing interests}

The authors declare that they have no competing interests.

\section{References}

1. Torre LA, Bray F, Siegel RL, Ferlay J, Lortet-Tieulent J and Jemal A: Global cancer statistics, 2012. CA Cancer J Clin 65: 87-108, 2015.

2. London WT and McGlynn KA: Liver cancer. In: Cancer Epidemiology and Prevention. Schottenfeld D and Fraumeni $\mathrm{J} \mathrm{Jr}_{\mathbf{r}}$ (eds). 3rd ed. Oxford University Press, New York, NY, pp763-786, 2006.

3. Wang X, Zhang A and Sun H: Power of metabolomics in diagnosis and biomarker discovery of hepatocellular carcinoma. Hepatology 57: 2072-2077, 2013.

4. Ye L and Jiang WG: Bone morphogenetic proteins in tumour associated angiogenesis and implication in cancer therapies. Cancer Lett 380: 586-597, 2015.

5. Naber HP, Wiercinska E, Pardali E, van Laar T, Nirmala E, Sundqvist A, van Dam H, van der Horst G, van der Pluijm G, Heckmann B, et al: BMP-7 inhibits TGF-beta-induced invasion of breast cancer cells through inhibition of integrin beta(3) expression. Cell Oncol (Dordr) 35: 19-28, 2012.

6. Buijs JT, van der Horst G, van den Hoogen C, Cheung H, de Rooij B, Kroon J, Petersen M, van Overveld PG, Pelger RC and van der Pluijm G: The BMP2/7 heterodimer inhibits the human breast cancer stem cell subpopulation and bone metastases formation. Oncogene 31: 2164-2174, 2012.

7. Tate CM, Pallini R, Ricci-Vitiani L, Dowless M, Shiyanova T, D'Alessandris GQ, Morgante L, Giannetti S, Larocca LM, di Martino S, et al: A BMP7 variant inhibits the tumorigenic potential of glioblastoma stem-like cells. Cell Death Differ 19: 1644-1654, 2012.

8. Hou F, Liu R, Liu X, Cui L, Wen Y, Yan S and Yin C: Attenuation of liver fibrosis by herbal compound 861 via upregulation of BMP-7/Smad signaling in the bile duct ligation model rat. Mol Med Rep 13: 4335-4342, 2016.

9. Ji X, Jin S, Qu X, Li K, Wang H, He H, He H, Guo F and Dong L: Lysine-specific demethylase 5C promotes hepatocellular carcinoma cell invasion through inhibition BMP7 expression. BMC Cancer 15: 801, 2015.
10. Liu J, Saito K, Maruya Y, Nakamura T, Yamada A, Fukumoto E, Ishikawa M, Iwamoto T, Miyazaki K, Yoshizaki K, et al: Mutant GDF5 enhances ameloblast differentiation via accelerated BMP2-induced Smad1/5/8 phosphorylation. Sci Rep 6: 23670, 2016.

11. Lopez-Coviella I, Mellott TM, Kovacheva VP, Berse B, Slack BE, Zemelko V, Schnitzler A and Blusztajn JK: Developmental pattern of expression of BMP receptors and Smads and activation of Smad1 and Smad5 by BMP9 in mouse basal forebrain. Brain Res 1088: 49-56, 2006.

12. Brazil DP, Church RH, Surae S, Godson C and Martin F: BMP signalling: Agony and antagony in the family. Trends Cell Biol 25: 249-264, 2015.

13. Boers W, Aarrass S, Linthorst C, Pinzani M, Elferink RO and Bosma P: Transcriptional profiling reveals novel markers of liver fibrogenesis: Gremlin and insulin-like growth factor-binding proteins. J Biol Chem 281: 16289-16295, 2006.

14. Guimei M, Baddour N, Elkaffash D, Abdou L and Taher Y: Gremlin in the pathogenesis of hepatocellular carcinoma complicating chronic hepatitis C: An immunohistochemical and PCR study of human liver biopsies. BMC Res Notes 5: 390, 2012.

15. Professional Committee of Chinese Anti-Cancer Association of liver cancer: Primary liver cancer diagnosis and staging criteria. Zhonghua Hepatology 9: 324, 2001.

16. Edge SB and Compton CC: The American Joint Committee on Cancer: The 7th edition of the AJCC cancer staging manual and the future of TNM. Ann Surg Oncol 17: 1471-1474, 2010.

17. Livak KJ and Schmittgen TD: Analysis of relative gene expression data using real-time quantitative PCR and the $2-\Delta \Delta \mathrm{Ct}$ method. Methods 25: 402-408, 2001.

18. Miao Y, Zong M, Jiang T, Yuan X, Guan S, Wang Y and Zhou D: A comparative analysis of ESM-1 and vascular endothelial cell marker (CD34/CD105) expression on pituitary adenoma invasion. Pituitary 19: 194-201, 2016.

19. Tejeda-Maldonado J, Garcia-Juarez I, Aguirre-Valadez J, Gonzalez-Aguirre A, Vilatoba-Chapa M, Armengol-Alonso A, Escobar-Penagos F, Torre A, Sánchez-Ávila JF and Carrillo-Pérez DL: Diagnosis and treatment of hepatocellular carcinoma: An update. World J Hepatol 7: 362-376, 2015.

20. Yang T, Chen SL, Lu XJ, Shen CY, Liu Y and Chen YP: Bone morphogenetic protein 7 suppresses the progression of hepatic fibrosis and regulates the expression of gremlin and transforming growth factor beta1. Mol Med Rep 6: 246-252, 2012.

21. Wang LP, Dong JZ, Xiong LJ, Shi KQ, Zou ZL, Zhang SN, Cao ST, Lin Z and Chen YP: BMP-7 attenuates liver fibrosis via regulation of epidermal growth factor receptor. Int J Clin Exp Pathol 7: 3537-3547, 2014.

22. Chen BL, Peng J,Li QF, Yang M, Wang Y and Chen W: Exogenous bone morphogenetic protein-7 reduces hepatic fibrosis in Schistosoma japonicum-infected mice via transforming growth factor-beta/Smad signaling. World J Gastroenterol 19: 1405-1415, 2013.

23. Jones CN, Tuleuova N, Lee JY, Ramanculov E, Reddi AH, Zern MA and Revzin A: Cultivating hepatocytes on printed arrays of HGF and BMP7 to characterize protective effects of these growth factors during in vitro alcohol injury. Biomaterials 31 : 5936-5944, 2010.

24. Li W, Cai HX, Ge XM, Li K, Xu WD and Shi WH: Prognostic significance of BMP7 as an oncogene in hepatocellular carcinoma. Tumour Biol 34: 669-674, 2013.

25. Zeisberg M, Yang C, Martino M, Duncan MB, Rieder F, Tanjore $\mathrm{H}$ and Kalluri R: Fibroblasts derive from hepatocytes in liver fibrosis via epithelial to mesenchymal transition. J Biol Chem 282: 23337-23347, 2007.

26. Aktug Demir N, Kolgelier S, Inkaya AC, Sumer S, Demir LS, Pehlivan FS, Arslan M and Arpaci A: Are bone morphogenetic protein-7 (BMP-7) serum levels correlated with development of hepatic fibrosis? J Infect Dev Ctries 8: 605-610, 2014.

27. Tacke F, Gabele E, Bataille F, Schwabe RF, Hellerbrand C, Klebl F, Straub RH, Luedde T, Manns MP, Trautwein C, et al: Bone morphogenetic protein 7 is elevated in patients with chronic liver disease and exerts fibrogenic effects on human hepatic stellate cells. Dig Dis Sci 52: 3404-3415, 2007.

28. Daniele B, Bencivenga A, Megna AS and Tinessa V: Alpha-fetoprotein and ultrasonography screening for hepatocellular carcinoma. Gastroenterology 127 (Suppl 1): S108-S112, 2004.

This work is licensed under a Creative Commons Attribution-NonCommercial-NoDerivatives 4.0 International (CC BY-NC-ND 4.0) License. 